\title{
Excerpts from Preface to First Edition
}

This volume represents accumulations from fifteen years of teaching the natural history of the invertebrates of the central California coast. . . .

In order to study animals in the field it is necessary to be able to identify them, to recognize them, and to know them by name. A considerable part of the time of the course, therefore, is devoted to the study in the laboratory of animals of the various groups with a view to learning the characteristics important in the identification of the species of these groups. ... No attempt is made to study taxonomy as such ... Our end is the prosaic one of learning names for the local assemblage as rapidly and simply as possible.

This end, unpretentious as it is, is by no means easily attained. The invertebrate animals of the Pacific Coast are very imperfectly known. For some there is no monographic account....

Furthermore, such monographs as do exist have a way of getting ou't of date. Thus, Richardson's monograph on the isopods (1905) is incomplete and badly in need of revision, and even so excellent a monograph as Schmitt's (1921), The Marine Decapod Crustacea of California, which we use to very great advantage, contains a number of names that have been changed since its publication.

Finally, modern monographs with keys would not be enough for our purpose. Limited time would still require that these be brought within the range of the study by simplification and limitation of terminology and by limitation of consideration to those species of the various groups significant in our local assemblages. Otherwise it would be impossible for the student to get that familiarity with the fauna as a whole which is one of the greatest values to be obtained in such a study....

The present work, incomplete as it is and continually in process of revision as it is, is the only one known to me which attempts to bring together in more or less completely illustrated keys and lists the informaxi 
\begin{tabular}{l|l} 
xii & $\begin{array}{l}\text { Excerpts from } \\
\text { Preface to First Edition }\end{array}$
\end{tabular}

tion necessary for even a tentative identification of the common invertebrates of this area. The work has been enriched by special studies made by students in the class and by graduate students specializing in the invertebrates....

Under the conditions existing with regard to our knowledge of Pacific Coast invertebrates, changes of name are bound to be the order of the day and a volume such as this is constantly undergoing revision as new works appear or new information is obtained. For its errors, which are numerous, probably beyond even the author's imagination, he accepts full responsibility, consoling himself by the hope that the knowledge of these errors, inevitably forced on the students' attention, may stimulate some of them to undertake corrective investigations such as those mentioned above....

Berkeley, California

S. F. Light

March, 1941 